\title{
ПРОБЛЕМА ВООБРАЖЕНИЯ В ПСИХОЛОГИИ (на примере анализа конструирования вербальных образов)
}

\author{
Шрагина Л.И. (Одесский национальный университет, Одесса, Украина) \\ larashragina@i.ua

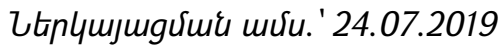

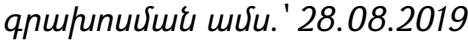

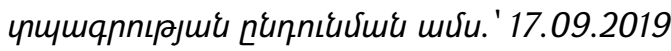

Наличие широкого диапазона взглядов на феномен «воображение» как психологическую основу творческой деятельности по созданию новых материальных и духовных ценностей позволяет утверждать, что этот феномен в научном представлении по-прежнему остается проблемой. В основе проблемы - противоречие: есть творческая деятельность, которая осуществляется посредством воображения, но само воображение как феномен при анализе исчезает, что вызывает необходимость рассматривать его на основе принципиально нового методологического подхода. В качестве такой методологии предложен функционально-системный подход. Рассмотрено, на основе предложенного подхода, функционирование вербального воображения в процессе создания вербального образа как искусственной системы. В терминах функционально-системного подхода «вербальное воображение» определяется как метасистема - комплекс определенных психических операций (действий) субъекта, который возникает и функционирует только при необходимости субъекта контролировать и управлять своими когнитивными процессами в ходе создания вербального образа.

Ключевые слова: искусственная система, функционально-системный подход, метасистема, вербальное воображение, метакогнитивные процессы.

В европейской культуре способность к творческой деятельности по созданию новых материальных и духовных ценностей неизменно связывалась с воображением. В западной же традиции универсальные творческие способности рассматриваются в концепции креативности, которая к концу XX - началу XXI столетия стала активно вытеснять понятие «воображение». Так, в современных монографиях по когнитивной психологии воображение как самостоятельная психическая функция не рассматривается. Исчезло "воображение» и из раздела «Познавательные процессы» многих современных учебников по общей психологии (в частности, «Психология XXI века» под ред. В.Н. Дружинина, 2003), что позволяет говорить о кризисе этого понятия. Возникает вопрос: связан ли данный кризис с очередным этапом развития и/или расширения понимания этого понятия или просто происходит его «конкурентная» подмена $[7,9,10]$ ? 
Анализ определений понятия «воображение», данных в научной литературе, начиная от Аристотеля и заканчивая работами авторов XX и XXI столетия, показал, что во всех определениях, несмотря на некоторые разногласия, функцией воображения признается процесс, который приводит к созданию различных видов образов. А существенными признаками воображения как психологического феномена признаны два: появление «новизны» в этих образах и взаимосвязь воображения с когнитивными и эмоциональными процессами.

Этот же анализ показал [9, 10], что психологическая природа воображения рассматривается как минимум в четырех аспектах:

- психическая деятельность по созданию новых образов [6];

- создание образов на основе мысленной программы («комбинирующий разум» [3], «словесно-логическое» [2], «познавательная деятельность» [4];

- воображение как самостоятельный психический процесс не существует, так как присутствует во всех фрормах и уровнях психического отражения [1];

- нечто, «функционирующее недеятельностно» [8].

Наличие столь широкого диапазона взглядов позволяет утверждать, что психологическая природа воображения в научном представлении по-прежнему остается проблемой, в основе которой - противоречие: есть творческая деятельность, которая осуществляется посредством воображения, но само воображение как психологический френомен при научном анализе исчезает. В результате традиционное понятие «воображение» остается расплывчатым и нестрогим, и для решения этой проблемы необходим ее анализ на иной методологической основе [9, 10].

И если кризис понимания сущности понятия "воображение» в психологии определяет актуальность данной темы, то необходимость выявления особенностей функционирования воображения как процесса и ответа на поставленный вопрос определяет цель исследования: выявить особенности и уникальность воображения как психического феномена.

Смоделируем деятельность, позволяющую опосредовано - через изучение ее содержательно-операциональных сторон - исследовать внутреннюю структуру психического процесса (в данном случае - воображения). В качестве модели такого процесса может выступить поиск решения имажинативной задачи.

Так как, изучая любую частную форму творчества, мы сталкиваемся и с его общими законами, сузим проблему, из всех функций воображения вычленим только ту их часть, которая связана с сознательной творческой деятельностью. В качестве объекта исследования рассмотрим функционирование одного из видов «воображения" (здесь и далее сохраним термин, но возьмем его в кавычки) вербального (словесно-логического), создающего вербальный образ “идеальных» объектов, то есть предметов и явлений, которые ранее частично или полностью в опыте человека не присутствовали. 
Под термином «вербальный образ» будем понимать представление (описание) объекта (явления, состояния) посредством группы слов, создающих своим объединением определенный смысл. Предметом исследования при этом выступают психологические механизмы ффункционирования вербального «воображения» в процессе поиска решения имажинативной задачи.

Вербальный образ как искусственная система, созданная с целью выполнения определенной (основной) функции, позволяет нам применить для анализа процесса его создания в качестве методологической основы функционально-системный подход - методологическое направление, одна из основных задач которого заключается в разработке и применении методов исследования сложноорганизованных и развивающихся объектов - систем.

В соответствии с классическим представлением о системе, ее системное свойство всегда больше простой суммы свойств структурных компонентов, объединенных в систему. Возникновение системного свойства при объединении компонентов и обеспечивает способность системы выполнять свою основную функцию - создавать системный эффрект.

Действия, которые создают из отдельных элементов систему, обладающую необходимым системным свойством и обеспечивающую достижение системного эфрфекта (результата), определим как системообразующая функция [5, 9, 10].

Применение данных понятий к анализу процесса конструирования вербального образа неизвестного объекта позволяет рассматривать вербальный образ как группу слов, объединенных общим смыслом и структурой в предложения, поэтому его создание можно рассматривать как процесс конструирования системы. Продуктом процесса вербализации образа (формой его существования) выступает текст - объект, который может быть проанализирован с позиций его структурных и содержательных компонентов. В нашем исследовании под функцией (назначением) вербального образа будем понимать передачу такой информации об объекте (явлении, состоянии), которая вызывает системный эффект эмоционально-смысловую реакцию, необходимую автору конструируемого образа. Эта реакция при конструировании вербального образа неизвестного объекта возникает как результат взаимодействия свойств взаимосвязанных компонентов, качественно-количественная представленность которых и определяет конечный «продукт» - системное свойство - индивидуальное своеобразие созданного образа, обладающего субъективным критерием «новизна». Процесс конструирования вербального образа как раз и представляет собой подбор этих структурных компонентов, взаимодействие которых обеспечивает организацию вербального образа как системы.

Было показано, что процесс конструирования вербального образа неизвестного объекта включает в себя:

- порождение его значения (семантизацию) - возникновение замысла; 
- разработку - подбор деталей (элементов), которые непосредственно и создают образ, в результате чего происходит реализация замысла.

Реализацию замысла - конструирование системы «вербальный образ» обеспечивают следующие основные психологические компоненты:

а) взаимосвязанные интеллектуальная активность и эмоциональная вовлеченность субъекта в процесс конструирования;

б) эмоционально-оценочное отношение к создаваемому образу;

в) актуальные знания (элементы «содержания»);

г) мыслительные приемы (комбинирование, аналогизирование, трансформации), с помощью которых субъект преобразует имеющиеся у него знания и конструирует нужный ему образ.

В результате взаимодействия этих компонентов появляется продукт - система «вербальный образ», который обладает субъективной новизной. При этом исследование показало, что способность к конструированию вербального образа положительно связана со способностью продуцировать ассоциации по сходству и визуальные образы.

В терминах функционально-системного подхода процесс конструирования вербального образа состоит из следующих этапов: возникающая у субъекта потребность выразить свое эмоционально-смысловое отношение к объекту (явлению, событию) проявляется как замысел - системообразующий фактор. Именно для реализации замысла субъект подбирает слова (элементы) и выстраивает их определенным образом (структурирует). Возникает новая система - вербальный образ. Структурная организация избранных слов создает системное свойство, которое и производит системный эффект - вызывает у читателя необходимую автору эмоционально-смысловую реакцию. То есть, чтобы такая реакция "состоялась», должны быть выполнены «управленческие-интегрирующие» действия - нужно оценить, отобрать и структурно организовать отдельные элементы. Как указывалось выше, эти действия - они создают из отдельных элементов систему, обладающую необходимым системным свойством и обеспечивающую достижение системного эфффекта (результата) - являются системообразующими и традиционно рассматривались как воображение.

Вышесказанное позволяет нам рассматривать «воображение», реализующее замысел при сознательной творческой деятельности, как системообразующую функцию - комплекс интегративных управленческих действий, выполняемых при решении творческих задач по оценке, отбору и структурированию элементов в систему $[9,10]$.

Результаты анализа функционирования вербального воображения при решении имажинативных задач с точки зрения когнитивных процессов позволяют нам отнести «вербальное воображение» к метакогнитивным процессам, которые выполняют управляюще-интегрирующую функцию, включая оценку и контроль 
над психическими процессами при возникновении у субъекта потребности создать вербальный образ.

А в терминах функционально-системного подхода «вербальное воображение» определим как метасистему - комплекс определенных психических операций (действий) субъекта, который возникает и функционирует только при необходимости субъекта контролировать и управлять своими когнитивными процессами в ходе создания вербального образа. Взаимодействие этих операций создает системное свойство, обеспечивающее субъекту способность контролировать и управлять процессом.

Это позволяет сделать вывод, что «вербальное воображение» как метасистема существует только в процессе, во время выполнения своей функции, поэтому форму его существования можно рассматривать как метасистемную функцию психическую функцию, выполняющую управляюще-интегрирующие действия.

Выводы. Предложенный автором функционально-системный подход позволяет согласовать противоречия во взглядах на психологическую природу вербального воображения и рассматривать его в творческом процессе как комплекс операций, реализующих системообразующую (в данном процессе - управляющеинтегрирующую) функцию и создающих новые системы. А психологический феномен, который традиционно определялся как «воображение» и «исчезал при анализе», можно отнести к метакогнитивным процессам - «процессам по управлению процессами».

Автор планирует применить разработанный вариант функциональносистемного подхода для анализа высших психических функций с целью уточнения механизмов их функционирования.

\section{Литература}

1. Брушлинский А.В. Субъект: мышление, учение, воображение. МоскваВоронеж. 1996. - 392 с.

2. Веккер Л. М. Психика и реальность: единая теория психических процессов. М.: Издательство «Смысл», 1998. - 685с.

3. Голосовкер Я. Имагинативная эстетика//Символ. Париж, 1993. №29. С.73130.

4. Коршунова Л.С., Пружинин Б.И. Воображение и рациональность. - М.: МГУ, 1989. - 182c.

5. Меерович М. Технология творческого мышления. Учебное пособие / Марк Меерович, Лариса Шрагина. - 2-е изд., испр. и доп. - М.: Альпина Паблишер, 2018. - 506 с.

6. Рубинштейн С.Л. Основы общей психологии. Т. 1. - М.: Педагогика, 1989.

7. Холодная М. А. Психология интеллекта. Парадоксы исследования. СПб.: Питер, 2002. - 272 c. 
8. Швал6 Ю.М. Целеполагающее сознание (психологические модели и исследования) /Ю. М. Швалб. - К. : Миллениум, 2003. - 152 с.

9. Шрагина Л. И. Психология вербального воображения: функциональносистемный подход. Монография. М.: СОЛОН-Пресс, 2018. - 272 с.

10. Шрагіна Л. І. Теоретико-методологічні засади дослідження вербальної уяви особистості : автореф. дис. на здобуття наук. ступеня доктора психол. наук : спец. 19.00.01 - Загальна психологія, історія психології / Л. І. Шрагіна. Київ, 2017. - 41 с.

\section{PROBLEM OF IMAGINATION IN PSYCHOLOGY (on the example of analysis of the construction of verbal images)}

Shragina L.I. (Odessa National University, Odessa, Ukraine)

The presence of a wide range of views on the phenomenon of "imagination" as the psychological basis of creative activity to developing new material and spiritual values suggests that this phenomenon in the scientific view is still a problem.

At the core of the problem is a contradiction: there is a creative activity that is carried out through imagination, but imagination itself as a phenomenon disappears during analysis, which makes it necessary to consider it on the basis of a fundamentally new methodological approach. As a methodology proposed functional system approach. Considered, on the basis of the proposed approach, the functioning of the verbal imagination in the process of creating a verbal image as an artificial system. In terms of the functional system approach, "verbal imagination" is defined as a metasystem - a complex of certain mental operations (actions) of a subject that arises and functions only when the subject needs to control and manage his cognitive processes during the creation of a verbal image.

Keywords: artificial system, functional-system approach, metasystem, verbal imagination, metacognitive processes. 